\title{
Multiple functional domains are involved in tomosyn regulation of exocytosis
}

\author{
Ofer Yizhar,* Noa Lipstein,* Svetlana E. Gladycheva, $†$ Ulf Matti, $₫$ Stephen A. Ernst, $\S$ Jens Rettig, $\ddagger$ \\ Edward L. Stuenkel $\dagger$ and Uri Ashery* \\ *Department of Neurobiochemistry, Life Sciences Institute, Tel Aviv University, Tel Aviv, Israel \\ $\dagger$ Department of Molecular and Integrative Physiology, University of Michigan, Ann Arbor, Michigan, USA \\ $\$$ Physiologisches Institut, Universität des Saarlandes, Homburg/Saar, Germany \\ $\S$ Department of Cell and Developmental Biology, University of Michigan, Ann Arbor, Michigan, USA
}

\begin{abstract}
Tomosyn is a cytoplasmic protein that was shown to bind to Syntaxin1 and SNAP-25 through an R-SNARE domain, forming a complex that is almost identical in structure to the neuronal SNARE complex. Tomosyn inhibits exocytosis in various cell types and these effects were attributed to direct competition between tomosyn's SNARE domain and Synaptobrevin/VAMP. In the present study, we investigated the contribution of different domains of tomosyn to its activity. We show that a tomosyn mutant that lacks the entire SNARE domain is a potent inhibitor of vesicle priming, similar to the full-length tomosyn. The SNARE domain of tomosyn failed to inhibit exocytosis, indicating that this domain is not required
\end{abstract}

for the inhibition. In contrast, over-expression of a N-terminally truncated mutant did not lead to inhibition of exocytosis although this mutant still bound to Syntaxin. Our results indicate that tomosyn can inhibit exocytosis independently of its SNARE interaction with Syntaxin and that the integrity of the WD40-domain is crucial for tomosyn's inhibitory function. Furthermore, we demonstrate that the entire $\mathrm{N}$-terminal region of tomosyn, the WD40-repeats and the linker, is required for tomosyn's inhibitory effect.

Keywords: chromaffin cells, exocytosis, priming, Syntaxin, tomosyn, WD40-repeats.

J. Neurochem. (2007) 103, 604-616.
Synaptic transmission occurs through the fusion of neurotransmitter-containing vesicles at pre-synaptic nerve endings. The amount of neurotransmitter released in response to stimulation determines the strength of the synaptic connection, and synaptic plasticity often involves changes in the quantity of released vesicles (Calakos and Scheller 1996; Henkel and Almers 1996; Neher 1998; Zucker and Regehr 2002; Reid et al. 2004). To undergo fusion, neurotransmitterloaded vesicles translocate to the plasma membrane and achieve a 'morphologically docked' state (Plattner et al. 1997). However, docked vesicles per se are not immediately capable of fusing with the membrane in response to stimulation (Augustine et al. 1999; Rettig and Neher 2002; Richmond and Broadie 2002; Sudhof 2004; Becherer and Rettig 2006). Rather, these vesicles need to undergo a molecular process described as 'priming' that renders them fusion-competent (Castillo et al. 2002; Lonart 2002; Rosenmund et al. 2002). The precise nature of this process is still unclear (Augustine et al. 1999; Fernandez-Chacon and Sudhof 1999; Rettig and Neher 2002; Sudhof 2004), but it appears to require a highly conserved set of proteins, which includes Syntaxin, SNAP-25, and Synaptobrevin (also known as VAMP) (Fasshauer et al. 1998). These proteins form a highly stable complex, the neuronal SNARE complex (Sutton et al. 1998; Weis and Scheller 1998), which plays an essential role in priming and in the fusion reaction itself (Hanson et al. 1997; Sutton et al. 1998; Weber et al. 1998; Gerst 1999; Jahn and Sudhof 1999).

The site of interaction between these three proteins is a fourhelix bundle, composed of two $\alpha$-helices from SNAP-25,

Received March 24, 2007; revised manuscript received May 30, 2007; accepted May 31, 2007.

Address correspondence and reprint requests to Uri Ashery, Department of Neurobiochemistry, Life Sciences Institute, Tel Aviv University, Tel Aviv 69978, Israel. E-mail: uria@post.tau.ac.il

Abbreviations used: CFP, cyan fluorescent protein; EGFP, enhanced green fluorescent protein; FRET, fluorescent resonant energy transfer; GFP, green fluorescent protein; GST, glutathione-S-transferase; GST, glutathione-S-transferase; PM, plasma membrane; RRP, readily releasable pool; TF, targeting factor. 
one from Syntaxin and one from Synaptobrevin (Fasshauer et al. 1998; Sutton et al. 1998). The number of fusioncompetent vesicles and the amount of exocytosis correlate with the ability to form SNARE complexes (Xu et al. 1998, 1999; Lonart and Sudhof 2000; Sørensen et al. 2002, 2003). These findings suggest that the assembly of SNARE complexes is associated with the priming step (Xu et al. 1999) and can modulate the amount of neurotransmitter release.

Tomosyn was first described as a novel binding partner for Syntaxin (Fujita et al. 1998). To date, two tomosyn genes are known in the mammalian genome. They are translated into seven alternatively spliced isoforms, some of which are ubiquitously expressed and some are brain-specific (Yokoyama et al. 1999; Groffen et al. 2005). The C-terminus of all tomosyn isoforms contains a coiled-coil domain with high homology to the Synaptobrevin coiled-coil domain. The 15 hydrophobic amino acids in the core of this domain are fully conserved between tomosyn and Synaptobrevin (Yokoyama et al. 1999; Groffen et al. 2005). Therefore, it was postulated that tomosyn belongs to a class of membrane trafficking regulators that utilize a SNARE motif to substitute for one of the components of the core complex (Masuda et al. 1998). At its N-terminus, tomosyn possesses multiple WD40repeats, homologous to several beta propeller-like proteins, such as Transducin, the G-protein $\beta$-subunit and several transcription factors (Lehman et al. 1999). WD40-repeat proteins have been shown to fold into a unique $\beta$-sheet propeller-like structure (Smith et al. 1999) that can reversibly form complexes with several proteins, thus coordinating sequential and/or simultaneous interactions with several partners (Neer et al. 1994). It therefore seems reasonable to assume that this domain plays an important role in the function of tomosyn, perhaps by interacting with proteins other than the SNARE complex.

Recent studies have shown that binding of tomosyn to Syntaxin and SNAP-25 through its C-terminal SNARE motif forms a four-helix bundle that is almost identical in its structure to the neuronal SNARE complex and that can be dissociated by the ATPase N-ethylmaleimide sensitive factor (Hatsuzawa et al. 2003; Pobbati et al. 2004). Over-expression of tomosyn caused a significant reduction in exocytosis in PC-12, chromaffin cells, adipocytes and beta cells, and inhibited synaptic transmission in neurons (Hatsuzawa et al. 2003; Widberg et al. 2003; Yizhar et al. 2004; Baba et al. 2005; Zhang et al. 2006). The notion that tomosyn acts as a negative regulator of synaptic transmission is supported by the finding that a $C$. elegans tomosyn null mutant shows increased levels of neurotransmitter release (Dybbs et al. 2005) through an enhancement of vesicle priming (Gracheva et al. 2006; McEwen et al. 2006). However, there are some indications that suggest that tomosyn might play a dual role in neurotransmitter release, since knock-down of tomosyn in neurons (Baba et al. 2005) and pancreatic beta-cells (Cheviet et al. 2006, but see also Zhang et al. 2006) caused a decrease in regulated exocytosis. These knock-down experiments suggest that tomosyn might also possess a positive role in exocytosis.

The inhibitory effects of tomosyn were attributed to its SNARE motif and it was postulated that tomosyn competes with Synaptobrevin for formation of SNARE complexes. It should be noted, however, that the SNARE motif of tomosyn binds to Syntaxin with relatively low affinity in vitro and that the full-length protein is needed for efficient Syntaxin binding (Yokoyama et al. 1999). Furthermore, proteins of the Lethal Giant Larvae ( $\mathrm{Lgl}$ ) family, that show significant homology to the N-terminal region of tomosyn, do not contain a well-defined SNARE motif, but are known to be involved in polarized secretion in yeast (Lehman et al. 1999), invertebrates (Betschinger et al. 2005) and mammals (Musch et al. 2002). The results of these studies are indicative of a conserved function for tomosyn homologs in secretion that does not necessarily involve SNARE interactions. Indeed, it was recently shown that the tomosyn homolog amysin (Scales et al. 2002), which was identified according to its tomosyn-like coiled-coil domain, can inhibit secretion independently of its interaction with Syntaxin (Constable et al. 2005) and that a tomosyn mutant that has a lower affinity to Syntaxin still inhibits secretion (Constable et al. 2005). However, the inhibition of this tomosyn mutant might be attributed to residual binding to Syntaxin. Thus, the role of the tomosyn SNARE motif in exocytosis remains unclear. In addition, the contribution of the WD40-repeats and the hypervariable linker, which constitute $90 \%$ of the protein, is completely unknown.

In the present study, we demonstrate that while the SNARE motif of tomosyn is critical for its interaction with Syntaxin, the inhibitory function of tomosyn can be carried out independently of this domain. We further show that the inhibitory effect requires an intact $\mathrm{N}$-terminal WD40-domain and that domains located C-terminally to the WD40-repeat area might possess some permissive activity. Moreover, we demonstrate that the minimal domain necessary for inhibition includes both the WD40-domain and the hypervariable linker region.

\section{Experimental procedures}

\footnotetext{
Plasmid and virus construction

Plasmids and viruses used for over-expression of full-length tomosyn and green fluorescent protein (GFP) were described previously (Yizhar et al. 2004). The truncated mutants of m-tomosyn were generated by PCR, cloned into pSFV1-GFP. For photobleach experiments, the different mutants were subcloned into a p-enhanced green fluoresecent protein (EGFP)-C1 vector, which contained the LoxP sequence using the Cre-recombinase-mediated Creator system (Clontech, Mountain View, CA, USA). The sequence of all constructs was verified by DNA sequencing.
} 


\section{Chromaffin cell preparation and infection}

Isolated bovine adrenal chromaffin cells were prepared and cultured as described before (Ashery et al. 1999; Yizhar et al. 2004). Cells were used 2-3 days after preparation. Infection was performed on cultured cells 5-48 h after plating (Ashery et al. 1999). Detection of GFP signal was performed using an IX-50 Olympus microscope with a filter set for enhanced GFP (TILL Photonics, Planegg, Germany).

\section{Fluorescence photobleaching and subcellular targeting of EGFP-tagged tomosyn}

Chromaffin cells were transfected with plasmid-coated $1.0 \mu \mathrm{m}$ diameter gold beads using a Helios Gene Gun (Bio-Rad Laboratories, Hercules, CA, USA). The gold beads were prepared according to the manufacturer's instructions. In all experiments where Syntaxin was expressed with EGFP-tomosyn or mutant tomosyn constructs, Munc18-1 was co-expressed to facilitate targeting of Syntaxin to the plasma membrane. Two days following transfection the cells were plated onto collagen-coated glass bottomed $35 \mathrm{~mm}$ culture dishes and imaged $24 \mathrm{~h}$ later in physiological saline containing (mmol/L): $\mathrm{NaCl}, 140, \mathrm{KCl}, 5, \mathrm{CaCl}_{2}, 2.2, \mathrm{MgCl}_{2}, 1$, glucose, 10 and HEPES, 10 (pH 7.4 adjusted with $\mathrm{NaOH}$ ). Subcellular targeting of expressed EGFP-tagged tomosyn or tomosyn constructs was determined following laser-induced (488 $\mathrm{nm}$ line of the argon laser) photobleach of EGFP fluorescence in a restricted region of the cytosol of live cells using either a Zeiss LSM 510 or an Olympus Fluoview confocal microscope (Zeiss, Göttingen, Germany). A targeting factor (TF) that quantifies distribution of EGFP-tagged proteins to the plasma membrane region was determined from images taken pre- and post-application of the photobleach. Initially, averaged fluorescence intensities of the whole cell $\left(I_{\text {tot }}\right)$ and its cytosolic $\left(I_{\mathrm{Cyt}}\right)$ and membrane $\left(I_{\mathrm{Mem}}\right)$ regions in pre- and post-bleach images were measured along with the corresponding total $\left(A_{\text {cyt }}\right)$, membrane $\left(A_{\text {mem }}\right)$ and cytosolic $\left(A_{\text {cyt }}\right)$ areas. Membrane targeting was defined as fraction of membranebound EGFP-tagged tomosyn to the total fluorescence of the cell before the photobleach. For each cell, relative membrane fluorescence parameter $M=\left(I_{\text {post }} / I_{\text {pre }}\right)^{\text {tot }}$ Mem was determined. Assuming that total intensity in a membrane region consists of contributions from that of membrane-bound and near-membrane cytosol fluorescence $\left(I_{\text {tot }}^{\text {mem }}=I_{\text {TrueMem }}+I_{\text {Cyt }} \cdot A_{\text {mem }}\right)$, and that $I_{\text {TrueMem }}$ does not change with photobleach, the targeting factor value was calculated as $\mathrm{TF}=I_{\text {TrueMem }} /\left(I_{\text {tot }}\right)_{\text {pre }}, \quad$ where $\quad I_{\text {TrueMem }}=\left[\left(I_{\text {pre }}\right)_{\text {cyt }} \cdot M-\left(I_{\text {post }}\right)_{\text {cyt }}\right]$ $A_{\text {mem }} /(1-M)$.

Confocal and conventional fluorescence microscopy of ECFPtomosyn and EcYFP-Syntaxin tagged proteins and imaging of FRET

Imaging of fluorescent resonant energy transfer (FRET) was carried out using acceptor photobleach (i.e., donor dequenching) methodology on the Zeiss confocal microscope. FRET imaging with the LSM 510 META relied on pixel-by pixel linear unmixing calculations (Meta software) performed prior to and following photobleach of the acceptor. Pre-bleach images were captured by sequential excitation of, cyan fluorescent protein (CFP) (FRET donor) and cYFP (FRET acceptor) with, respectively, a blue diode laser at $505 \mathrm{~nm}$ and the $515 \mathrm{~nm}$ line of an argon laser, both at low (2\%) transmission to minimize acquisition bleach. cYFP in a pre- defined region of interest (part of or whole cell) was then bleached with the 515 laser line at $100 \%$ transmission to achieve approximately $90 \%$ loss of acceptor fluorescence. Immediately thereafter, a post-bleach image was captured of CFP and cYFP using the same parameters as those used for pre-bleach images. Relative FRET efficiency by acceptor photobleach was calculated as (1-[ECFP $I_{\text {pre- }}$ bleach $/$ ECFP $\left.\left.I_{\text {post-bleach }}\right]\right) \times 100 \%$. The confocal microscope was optimal for acquiring images in a single optical plane coincident with FRET and analysis of its subcellular compartmentation.

\section{Pulldown experiments and western blotting}

Syntaxin1A (aa 1-264) was expressed in E. coli as a glutathione-Stransferase (GST)-fusion protein. GST was expressed in a similar manner and both proteins were purified by glutathione-Sepharose (Sigma, St Louis, MO, USA). 150 pmol of purified GST, GSTSyntaxin1A or GST-SNAP25 were incubated with glutathioneSepharose at $4{ }^{\circ} \mathrm{C}$ and excess proteins were removed by three washes with phosphate-buffered saline. GFP-tagged tomosyn mutants were expressed in PC-12 cells by infection with Semliki forest virus (SFV). Lysates prepared from the cells ( $10^{7}$ cells for each infection) $12 \mathrm{~h}$ after infection were incubated with the coated beads for $16 \mathrm{~h}$ at $4^{\circ} \mathrm{C}$ in lysis buffer $(100 \mathrm{mmol} / \mathrm{L} \mathrm{KCl}, 20 \mathrm{mmol} / \mathrm{L}$ HEPES-KOH, $2 \mathrm{mmol} / \mathrm{L}$ EDTA, $1 \%$ Triton $\mathrm{X}-100,1 \mathrm{mmol} / \mathrm{L}$ dithiothreitol) with protease inhibitor cocktail (Roche, PI Complete). The beads were washed four times with phosphate-buffered saline and bound proteins were analyzed by SDS-PAGE and immunoblotting with anti-GFP antibody (Clontech, dilution 1 : 4000). GST-Syntaxin1A, GST-SNAP25 and GST plasmids were a kind gift of Prof. Ilana Lotan.

\section{Membrane capacitance measurements}

Conventional whole-cell recordings and capacitance measurements were performed as detailed before (Yizhar et al. 2004; Nili et al. 2006) and analyzed using Igor Pro (Wavemetrics Inc.). The external bathing solution contained (in mmol/L): $140 \mathrm{NaCl}, 3 \mathrm{KCl}, 2 \mathrm{CaCl}_{2}$, $1 \mathrm{MgCl}_{2}, 10$ HEPES and $2 \mathrm{mg} / \mathrm{mL}$ glucose $\mathrm{pH} 7.2$ (320 mOsm). For flash photolysis experiments the internal pipette solution consisted of (in mmol/L): 105 cesium glutamate, $2 \mathrm{MgATP}, 0.3$ GTP, 33 HEPES, 0.33 fura-2FF (TefLabs, Austin, TX) (300 mOsm). The basal calcium was buffered by a combination of $4 \mathrm{mmol} / \mathrm{L}$ $\mathrm{CaCl}_{2}$ and $5 \mathrm{mmol} / \mathrm{L}$ NP-EGTA (G. Ellis-Davis; MCP, Hahnemann University, Philadelphia) to give a free $\left[\mathrm{Ca}^{2+}\right]_{\mathrm{i}}$ of $300 \mathrm{nmol} / \mathrm{L}$ (Yizhar et al. 2004; Nili et al. 2006). Experiments were performed $8-16 \mathrm{~h}$ after infection at $30-32^{\circ} \mathrm{C}$.

\section{Photolysis of caged $\mathrm{Ca}^{2+}, \mathrm{Ca}^{2+}$ ramp experiments and $\left[\mathrm{Ca}^{2+}\right]_{\mathrm{i}}$} measurements

Flashes of UV light were generated by a flash lamp (TILL Photonics) and fluorescent excitation light was generated by a monochromator (TILL Photonics). The monochromator and flash lamp were coupled using a Dual Port condenser (TILL Photonics) into the epifluorescence port of an IX-50 Olympus microscope equipped with a $40 \times$ objective (UAPO/340; Olympus, Japan). Fura-2FF was excited at 350/380 nm and detected through a $500 \mathrm{~nm}$ long pass filter (TILL Photonics). Photolysis experiments were done as described before (Xu et al. 1998; Ashery et al. 2000; Yizhar et al. 2004). Calcium ramps were elicited by the fluorescence excitation light alternating between 350 and $380 \mathrm{~nm}$ such that photolysis of nitrophenyl-EGTA could be combined with simultaneous measurement of $\left[\mathrm{Ca}^{2+}\right]_{\mathrm{i}}$. Rate constants 
calculation was done as described before (Xu and Bajjalieh 2001; Sørensen et al. 2002; Yizhar et al. 2004). Rate constants from several cells were binned according to the corresponding calcium values to create the plot of rate constants versus $\left[\mathrm{Ca}^{2+}\right]_{\mathrm{i}}$ on a double logarithmic scale (Fig. 3e) (Sørensen et al. 2002). Given values represent mean \pm SEM. For statistical comparisons, data distributions were tested for similarity using the Kolmogorov-Smirnov test and the means were compared using Student's $t$-test. Where indicated, the Mann-Whitney rank-sum test was used to compare data distributions that significantly differed from each other.

\section{Results}

Tomosyn contains in its C-terminal region a coiled-coil domain that is highly homologous to the vesicle membrane protein VAMP/Synaptobrevin 2. Its large N-terminal region contains several WD-repeats that are predicted to fold into a beta-propeller structure (Pobbati et al. 2004) (Fig. 1). In previous studies, the inhibitory effect of tomosyn has been ascribed to the binding of its SNARE motif to Syntaxin (Fujita et al. 1998; Hatsuzawa et al. 2003; Widberg et al. 2003; Pobbati et al. 2004). It was predicted that the SNARE motif competes with endogenous Synaptobrevin for the formation of SNARE complexes and thus reduces the amount of release-competent vesicles (Hatsuzawa et al. 2003). In this study, we investigated the contributions of the different domains of tomosyn to its inhibitory activity in regulated exocytosis. To that end, we constructed a set of truncated tomosyn mutants (Fig. 1a) and expressed these proteins fused to GFP using the Semliki Forest Virus (SFV) system in bovine adrenal chromaffin cells (Yizhar et al. 2004). The expression of the different fusion proteins was detected using western blot analysis with anti-GFP and antitomosyn antibodies and by quantitation of GFP fluorescence in infected cells (Fig. 1b,c and Supplementary Fig. S1). As we showed previously, there is a linear relation between GFP fluorescence and tomosyn levels (Yizhar et al. 2004), and therefore, only cells that showed similar levels of GFP fluorescence were chosen for electrophysiological measurements (Fig. 1c). We then examined the interactions of these mutants with Syntaxin1A and the effects of their overexpression on exocytosis in bovine adrenal chromaffin cells.

\section{Binding of tomosyn to Syntaxin is mediated by the SNARE motif}

We performed two sets of experiments to test for the ability of the different tomosyn mutants to bind to Syntaxin in vitro and in vivo. We first used a pulldown assay to test the ability of the different mutants to bind to Syntaxin in vitro. PC-12 cells were infected with SFV to express the different mutants as GFP-fusion proteins. Lysates prepared from these cells were incubated with sepharose beads coated with GST or with GST-Syntaxin1A. After extensive washing, the bound proteins were analyzed by SDS-PAGE and immunoblotted (a)

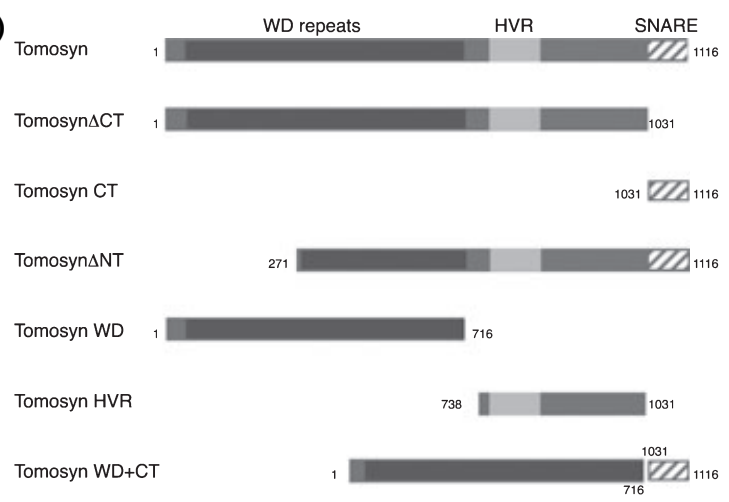

(b)

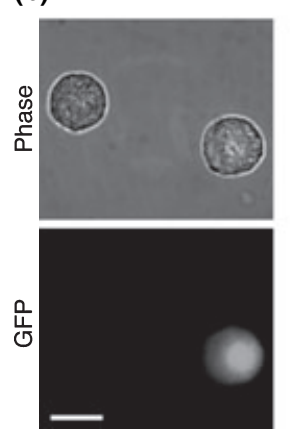

(c)

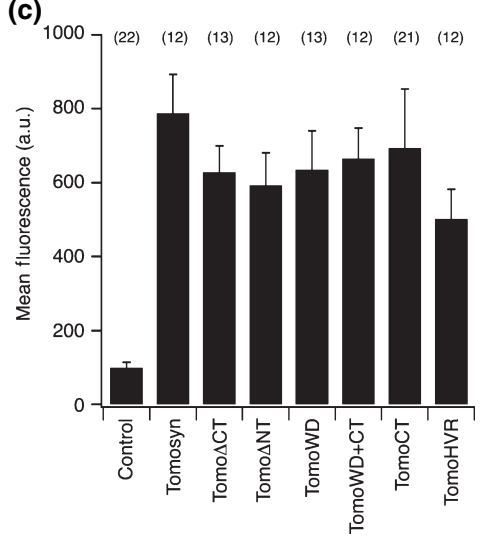

Fig. 1 Tomosyn mutants used in this study and expression levels. The various sequence elements are depicted at the top of the diagram - WD-repeats located at the $\sim 700 \mathrm{~N}$-terminal amino acids (dark gray), a hyper variable linker region (aa 704-770, light gray) and the RSNARE motif at the C-terminus (aa 1051-1116, diagonal lines). The amino acid numbers at which each mutant begins and ends are shown on the diagrams. ( $b$ and $c$ ) Expression of tomosyn GFP-fusion proteins in chromaffin cells. (b) Fluorescence and phase-contrast images of two cultured chromaffin cells from a culture dish infected with SFV to express GFP-tomosyn. The outline of the cell was selected according to the phase-contrast image and mean fluorescence intensity was calculated to quantify the level of expression. We have previously shown that the fluorescence intensity of GFP in these cells correlates linearly with the immunofluorescent signal detected using anti-tomosyn antibody (Yizhar et al. 2004) and is therefore a good measure of expression levels. (c) Fluorescence intensity in control (uninfected) cells and cells expressing the different tomosyn mutants used in this study (mean \pm SEM; $n$ is indicated above each column). All tomosyn mutants showed similar levels of expression, which we estimate to be 10-15 times the level of endogenous tomosyn (Yizhar et al. 2004).

with anti-GFP to identify the exogenously expressed proteins (Fig. 2a, left panel). Some of the tomosyn mutants migrated in the gel as double bands (Widberg et al. 2003; Yizhar et al. 2004), the nature of which is under investigation. Our results show that all the mutants that contain the SNARE motif, i.e., tomosyn, tomosyn $\triangle \mathrm{NT}$ and tomosynCT, bound to GSTSyntaxin. Binding of tomosyn $\Delta$ CT to GST-Syntaxin was not detected despite the fact that this mutant was expressed at a 


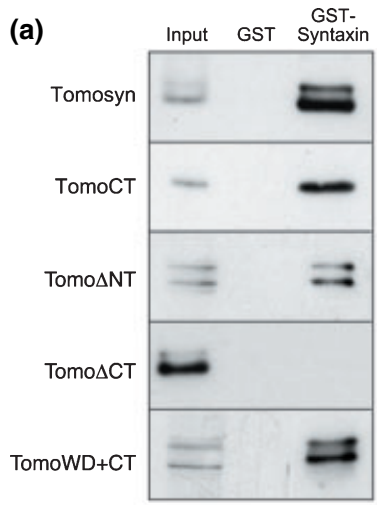

(c)



(f)

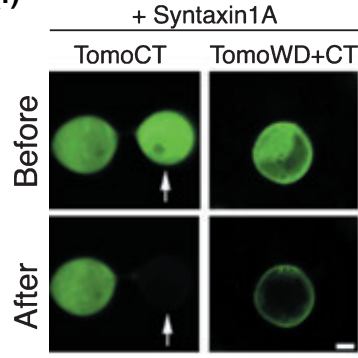

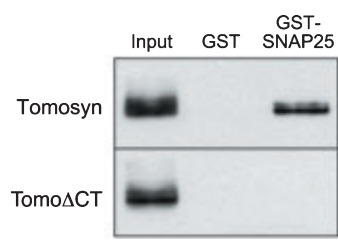

(b)

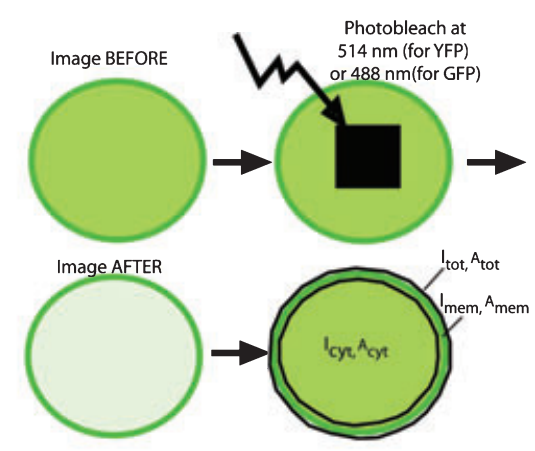

(d)

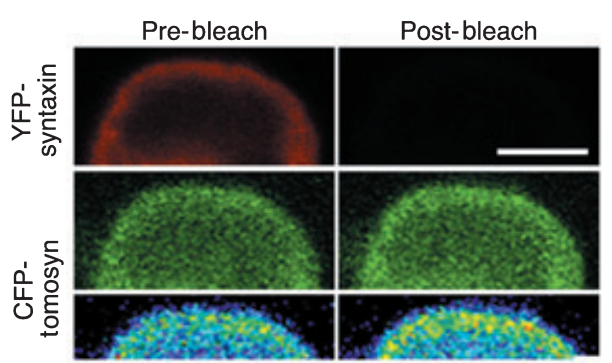

(e)

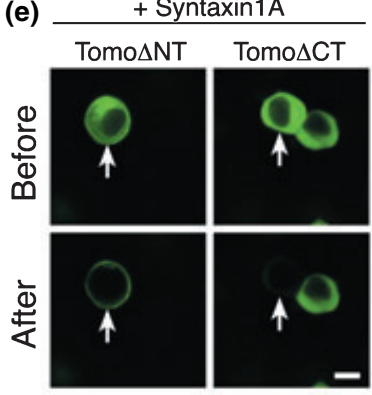

(g)

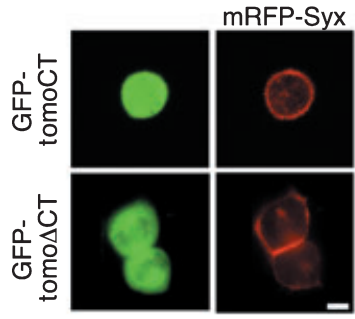

(h)

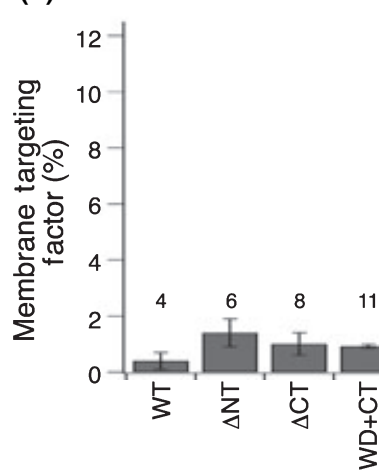

$\stackrel{11}{*} 9$
Fig. 2 Binding of tomosyn and mutants to Syntaxin in vitro and in vivo. (a) GST-Syntaxin (left panel) and GST-SNAP-25 (right panel) pulldown assay of GFP-fused tomosyn and the indicated truncation mutants. Lysates from PC-12 cells expressing the indicated GFPfused proteins (left lanes, 10\% of total) were bound to GST-(middle lanes) or GST-Syntaxin or GST-SNAP-25 beads (right lanes). Bound proteins were analyzed by SDS-PAGE and immunoblotted with antiGFP antibody. (b) Photobleaching of freely diffusible GFP-fused proteins uncovers membrane-associated fluorescence in a live cell. A detailed description of the procedure is given in the Experimental procedures section. (c) EGFP-tomosyn was expressed in chromaffin cells and the cells indicated by an arrowhead were subjected to a brief spatially delimited photobleach of freely diffusible GFP. A membranebound fraction is not observed following photobleaching, indicating that most GFP-tomosyn is cytoplasmic. Similarly, GFP-tomosyn $\Delta C T$ and GFP-tomosyn $\triangle$ NT did not show membrane targeting. (d) Left and right image columns show images taken before and following, respectively, photobleaching (at $515 \mathrm{~nm}$ argon laser line) of the YFP fluorescence. Increased post-bleach CFP intensity indicates FRET between CFP-tomosyn and cYFP-Syntaxin1A. A pseudocolored representation of CFP intensity in the photobleached region is shown below the image sets for pre and post-bleach conditions. (e) Syntaxin was co-expressed with the tomosyn mutants. A membrane-bound fraction is observable after photobleaching of the indicated cells (arrowheads) in tomosyn and tomosyn $\Delta$ NT but not tomosyn $\Delta$ CT cells. (f) GFP-tomosynCT did not show detectable membrane targeting, when co-expressed with Syntaxin (left panels). Tomosyn WD+CT was targeted to the membrane indistinguishably from full-length tomosyn (right panels). (g) mRFP-Syntaxin is localized to the plasma membrane in cells over-expressing either GFP-tomosyn, GFP-tomosynCT or GFP-tomosyn $\triangle \mathrm{CT}$. (h) Membrane targeting factors calculated for the experiments depicted in C-E. Data are shown as mean \pm SEM and the number of cells in each experiment is indicated above the bars. Statistical significance was calculated using a two-tailed student's $t$-test $\left({ }^{*} p<0.05\right)$. Scale bars, $5 \mu \mathrm{m}$. 
(a)

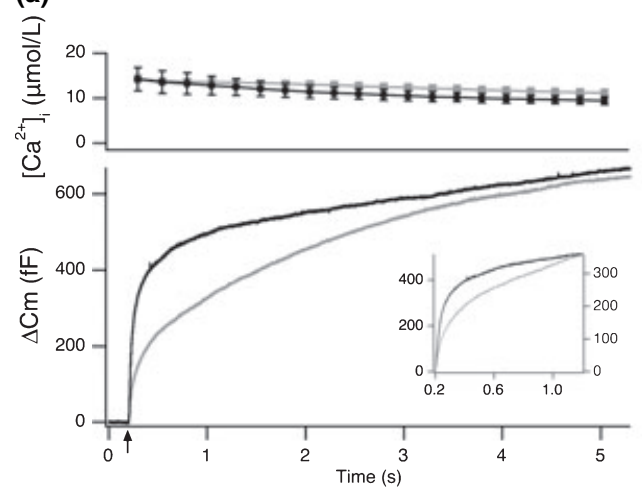

(b)

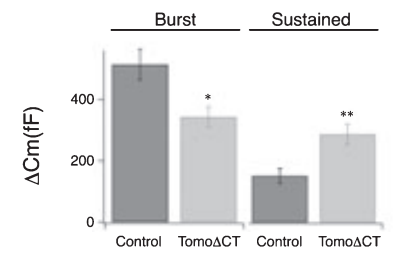

(d)
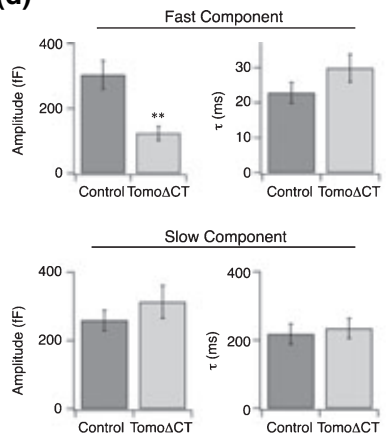

(c)
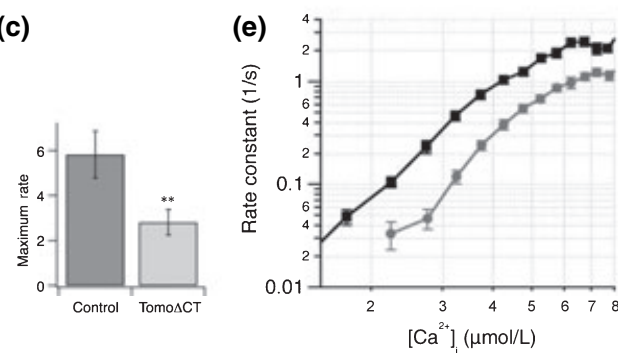

Fig. 3 Tomosyn $\Delta C T$ inhibits exocytosis in chromaffin cells by reducing the size of the RRP. (a) Averaged calcium ([ $\left.\mathrm{Ca}^{2+}\right]_{\text {i }}$, top trace) and capacitance change ( $\mathrm{Cm}$, bottom trace) in control cells (black, $n=30$ ) and cells over-expressing tomosyn $\triangle \mathrm{CT}$ (gray, $n=42$ ). Arrow indicates the time of flash stimulation. Inset shows the mean capacitance change for tomosyn $\Delta \mathrm{CT}$ cells, normalized to the amplitude of control data at $1 \mathrm{~s}$ after the flash. (b) Expression of tomosyn $\triangle \mathrm{CT}$ caused a singnificant reduction in the average capacitance increase during the exocytotic burst ( $342 \pm 32 \mathrm{fF}$ tomosyn $\Delta \mathrm{CT}, 514 \pm 49 \mathrm{fF}$ control) while the sustained component was enhanced $(288 \pm 33 \mathrm{fF}$ tomosyn $\Delta \mathrm{CT}$, $152 \pm 24 \mathrm{fF}$ control). (c) The maximum rate of secretion in tomosyn $\triangle C T$ cells was dramatically reduced as compared to control $(2.8 \pm 0.55 \mathrm{pF} / \mathrm{s}$ tomosyn $\Delta \mathrm{CT}, 5.8 \pm 1.01 \mathrm{pF} / \mathrm{s}$ control). (d) A significant reduction in the amplitude of the fast component of the exocytotic

level similar to that of the other mutants (Figs 1c and 2a left panel and Supplementary Fig. S1). These experiments confirmed that the SNARE-homology domain of tomosyn is both required and sufficient for binding to Syntaxin in vitro. Nevertheless, these experiments cannot exclude the possibility that transient low affinity interaction with Syntaxin occur through other parts of tomosyn (Lehman et al. 1999). It has recently been shown that the yeast homolog of tomosyn Sro7 interacts with Sec9, the yeast SNAP-25 homolog (Hattendorf et al. 2007). We therefore examined whether the interaction of tomosyn with SNAP-25 depends on tomosyn's SNARE motif. In a SNAP-25 pulldown assay, tomosyn bound to beads coated with GST-SNAP-25 while tomosyn $\Delta$ CT did not show any binding, indicating that the SNARE-homology domain of tomosyn is critical for the binding to SNAP-25 (Fig. 2a, right panel).

While these experiments provided an indication that the SNARE motif is indeed required for binding of tomosyn to burst occurred in tomosyn $\Delta \mathrm{CT}$ cells $(123 \pm 21 \mathrm{fF}$ tomosyn $\Delta \mathrm{CT}$, $302 \pm 44 \mathrm{fF}$ control) while the amplitude of the slow component and the time constants of both components remained unchanged. (e) A calcium ramp experiment was performed by slow release of $\mathrm{Ca}^{2+}$ from NP-EGTA using weak UV-illumination. The rate constants of secretion are plotted against calcium in control cells (black squares, $n=11$ ), and cells over-expressing tomosyn $\Delta C T$ (gray circles, $n=18$ ). Cells overexpressing tomosyn $\Delta \mathrm{CT}$ secreted with slower rate constants than control for equivalent calcium concentrations. The calcium-dependence curve for tomosyn $\Delta \mathrm{CT}$ cells was shifted toward higher calcium concentrations, but its slope remained unchanged. Bar graphs represent mean \pm SEM. ${ }^{*} p<0.05$ (Student's $t$-test), ${ }^{* *} p<0.005$ (MannWhitney rank-sum test).

GST-Syntaxin in vitro, we wanted to examine whether this is true for the interaction of tomosyn and Syntaxin within living cells. We therefore performed a set of photobleach experiments where the interaction of the different tomosyn mutants, expressed as EGFP-fused proteins, with membrane-bound Syntaxin was determined in live chromaffin cells. This experimental approach selectively removes the contribution of cytosolic EGFP-tomosyn to the fluorescent image of the cell by application of brief laser photobleaching, using a laser scanning confocal microscope, within a discrete area in the cell's cytoplasm (Fig. 2b). The remaining EGFP fluorescence reflected EGFP-tomosyn that was diffusionally restricted, presumably through its specific interaction with Syntaxin or other proteins associated with membrane delimited organelles or the plasma membrane. To quantify the level of Syntaxin-binding by tomosyn and its truncated mutants, we calculated a membrane-targeting factor (TF) for each GFPfusion protein (Fig. 2b, see also Experimental procedures). 
This enabled a quantitative comparison of the ability of these proteins to bind to Syntaxin under physiological conditions within a live cell.

Over-expressed GFP-tomosyn was observed mostly as a diffuse cytosolic fluorescence, similar to the reported distribution of the endogenous protein. Following photobleaching of a spot region in the cytoplasm, most of the GFP-tomosyn fluorescence was lost (Fig. 2c, left panel). However, when GFP-tomosyn was co-over-expressed with Syntaxin1A, we could detect a membrane-bound fraction of GFP-tomosyn that remained after most of the cytoplasmic GFP-tomosyn was photobleached (Fig. 2c, right panel). Indeed, the TF calculated for GFP-tomosyn was significantly higher than without co-over-expression of Syntaxin (TF: $11.4 \pm 1.1$ and $0.4 \pm 0.3$, respectively; Fig. $2 \mathrm{~h}$ ). Under these conditions, over-expressed Syntaxin is also concentrated on the plasma membrane (Fig. 2d). As the affinity between Syntaxin and tomosyn is known to be high and since tomosyn is not found at the plasma membrane without co-over-expression of Syntaxin, we conclude that that GFP-tomosyn co-localizes with membrane-resident Syntaxin in live cells. This colocalization might result from direct molecular interaction between Syntaxin and tomosyn or indirectly via other proteins. To differentiate between these possibilities we used FRET between the CFP/cYFP pair to visualize and quantify direct CFP-tomosyn/cYFP-Syntaxin1A interactions. FRET measurements were performed by acceptor photobleach on fixed cells using an Olympus Fluoview 500 confocal microscope. Fig. 2d compares images acquired prior to and following a localized photobleach of the cYFP acceptor at the plasma membrane regions of two adjoining cells. A marked increase in CFP fluorescence occurred following photobleach that was restricted to the bleached plasma membrane area, a result indicative of FRET between CFPtomosyn and cYFP-Syntaxin1A. The increased CFP signal following photobleach was readily apparent on comparison of pseudocolored images of the plasma membrane prior to and following photobleach (shown below cell images). Averaged relative FRET efficiency values for photobleached and non-photobleached plasma membrane regions was $11.2 \%$ and this clearly establishes tomosyn is found on the plasma membrane (PM) in direct molecular interaction with Syntaxin. Most probably, these tomosyn-Syntaxin complexes also contain SNAP-25 (Fig. 2a, and see Pobbati et al. 2004).

We next performed a cytosolic bleach experiment with cells expressing GFP-tomosyn $\Delta \mathrm{CT}$ and GFP-tomosyn $\Delta \mathrm{NT}$. In agreement with our in vitro experiments (Fig. 2a), we did not observe a membrane-bound fraction in cells overexpressing GFP-tomosyn $\Delta$ CT (Fig. 2e,h) although Syntaxin was localized to the plasma membrane in these cells (Fig. 2g). In contrast, in cells expressing GFP-tomosyn $\Delta \mathrm{NT}$, a membrane-bound fraction was observed that was similar in its intensity to that of full-length tomosyn (Fig. 2e). The targeting factor calculated for this mutant was indistinguish- able from the TF of full-length tomosyn (TF: $11 \pm 1.3$ and $11.4 \pm 1.1$, respectively; Fig. $2 \mathrm{~h}$ ). This experiment supports the hypothesis that the interaction of tomosyn with Syntaxin is mediated via a protein domain that exists in both tomosyn and tomosyn $\Delta \mathrm{NT}$, probably the coiled-coil domain. We therefore performed a similar experiment with tomosynCT. Surprisingly, in cells expressing this mutant we could not detect membrane-bound fluorescence (Fig. 2f,h), although the expression level of tomosynCT was similar to that of the other mutants (Figs 1c and 2a, left panel, and Supplementary Fig. S1) and Syntaxin was properly localized to the plasma membrane in these cells (Fig. $2 \mathrm{~g}$ ). This is in apparent contrast to the binding of this protein to GST-Syntaxin in the pulldown experiment (Fig. 2a). These results imply that either the SNARE motif is not sufficient to support binding of tomosyn to Syntaxin in a live cell or that, most probably, this interaction is weaker and therefore not detectable using this assay.

\section{Deletion of the C-terminal SNARE motif does not abolish tomosyn's inhibitory function}

In a previous study, we have shown that over-expression of tomosyn caused a significant decrease in the exocytotic response and concluded that tomosyn inhibits priming of vesicles (Yizhar et al. 2004). Since it is generally believed that the inhibitory effect is attributed to the SNARE motif, we wanted to examine the effect of a deletion of this domain on the inhibitory activity of tomosyn. We therefore overexpressed tomosyn $\Delta \mathrm{CT}$ in bovine chromaffin cells and examined the effect of this mutant on exocytosis. Exocytosis was stimulated by a step-like increase in intracellular calcium caused by photolysis of the calcium cage NP-EGTA by a flash of UV light. In response to elevation of intracellular calcium $\left(\left[\mathrm{Ca}^{2+}\right]_{\mathrm{i}}\right)$, control cells displayed a typical biphasic increase in membrane capacitance in which an exocytotic burst was followed by a sustained phase of secretion (Fig. 3a). The exocytotic burst results from the fusion of a pool of fusion-competent vesicles, while the sustained phase represents the fusion of vesicles that are mobilized and undergo priming from the unprimed pool (UPP) during the calcium pulse (Voets et al. 1999). In cells over-expressing tomosyn $\Delta \mathrm{CT}$, the exocytotic burst was significantly reduced in comparison with that of control cells $(342 \pm 32 \mathrm{fF}$ vs. $514 \pm 49 \mathrm{fF}$; Fig. 3a,b). In contrast, the sustained phase of secretion was larger in tomosyn $\Delta \mathrm{CT}$ cells than in the control cells $(288 \pm 33 \mathrm{fF}$ vs. $152 \pm 24 \mathrm{fF}$; Fig. 3a,b). Additionally, a significant decrease occurred in the maximal rate of secretion in cells expressing tomosyn $\Delta \mathrm{CT}$ (Fig. 3c). The reduction in the exocytotic burst is similar to the effect that was previously observed with full-length tomosyn. For comparison, the exocytotic burst in cells over-expressing full-length tomosyn was decreased by $51 \%$ while the sustained component was enhanced by $56 \%$ (Yizhar et al. 2004). The enhanced sustained component observed both in 
tomosyn and tomosyn $\Delta \mathrm{CT}$ indicate that during intense stimulation the inhibitory effect of tomosyn is relieved and priming proceeds at a higher rate, most likely due to the high calcium concentration during the stimulation period. It is also possible that under these experimental conditions, the larger sustained component represents a permissive role for tomosyn. This is in good agreements with the findings that tomosyn knockdown in neurons and in pancreatic beta-cells caused a decrease in regulated secretion (Baba et al. 2005; Cheviet et al. 2006), suggesting a positive role for tomosyn in exocytosis in addition to its characterized inhibitory activity. Thus, we can divide tomosyn effects into two phases; an initial inhibition that is followed by the relief of the inhibition or alternatively can be attributed to some permissive role of tomosyn.

Previous studies in chromaffin cells have shown that the exocytotic burst can be further resolved into two distinct kinetic components. The fast component $(\tau \sim 30 \mathrm{~ms})$ results from fusion of vesicles from the readily releasable pool (RRP) while the slow phase ( $\tau \sim 300 \mathrm{~ms}$ ) represents fusion of vesicles from the slowly releasable pool [SRP; Xu et al. (1998)]. We asked which of the kinetic components of the exocytotic burst was affected by tomosyn $\Delta C T$. Fitting the capacitance traces from the responses of cells over-expressing tomosyn $\Delta \mathrm{CT}$ with a double-exponential function showed that the RRP size was decreased by $\sim 60 \%$ upon overexpression of tomosyn $\Delta \mathrm{CT}(123 \pm 21 \mathrm{fF}$ in tomosyn $\Delta \mathrm{CT}$, $302 \pm 44 \mathrm{fF}$ in control; Fig. 3d). The amplitude of the slow phase, in which vesicles fuse from the SRP, was indistinguishable from control. The time constants of both phases were similar to those of control cells, indicating that the last steps of vesicle fusion are not affected by over-expression of tomosyn $\Delta \mathrm{CT}$ (Fig. 3d). A similar, albeit stronger reduction in the size of the RRP was observed when the full-length tomosyn protein was over-expressed $(\sim 87 \%$ reduction; (Yizhar et al. 2004).

An additional effect of tomosyn over-expression was the shift in the calcium-secretion curve to higher calcium concentrations (Yizhar et al. 2004). To examine whether the same occurs with tomosyn $\Delta \mathrm{CT}$, we performed a calcium ramp experiment in which $\left[\mathrm{Ca}^{2+}\right]_{i}$ was slowly elevated by monochromator-based photolysis of NP-EGTA. The rate of secretion at each $\left[\mathrm{Ca}^{2+}\right]_{i}$ was then calculated from the capacitance trace. Comparison of the calcium-secretion curves from control vs. tomosyn $\Delta \mathrm{CT}$ cells (Fig. 3e) shows that over-expression of tomosyn $\Delta \mathrm{CT}$ causes a shift in the calcium-dependence of exocytosis towards higher calcium concentrations. However, the slopes of the two curves are identical, indicating that the calcium cooperativity of exocytosis remains unchanged. Interestingly, the shift in calciumdependence is identical to that observed with full-length tomosyn (Yizhar et al. 2004). This result, together with the specific reduction in the size of the RRP, led us to conclude that deletion of the SNARE motif does not abolish the inhibitory effects of tomosyn on exocytosis, arguing that a different region of the protein must be involved in mediating the inhibition.

\section{Over-expression of the tomosyn SNARE motif does not lead to inhibition of exocytosis}

Previous studies have used in vitro and semi in vitro systems to examine the effects of the addition of synthetic SNARE motif-containing peptides on calcium-dependent exocytosis (Hatsuzawa et al. 2003; Schuette et al. 2004). In these experiments, the SNARE motif of tomosyn caused inhibition of membrane fusion, probably by competing with vesicle membrane-bound Synaptobrevin for the formation of SNARE complexes. Based on these results, it was hypothesized that tomosyn inhibits exocytosis by acting as a soluble competitor to Synaptobrevin in the formation of SNARE complexes. We asked whether the same inhibition would occur when this fragment was over-expressed in intact cells. Over-expression of tomosynCT (Fig. 1a) was verified by immunoblot analysis (Supplementary Fig. S1) and by measuring the level of GFP fluorescence (Fig. 1c) and exocytosis was examined in over-expressing cells by flash photolysis of caged calcium. The size of the exocytotic burst in the responses of cells over-expressing tomosynCT was similar to the exocytotic burst of control cells (Fig. 4b). However, cells expressing tomosynCT showed an increased sustained component, indicating that under conditions of elevated $\left[\mathrm{Ca}^{2+}\right]_{\mathrm{i}}$, priming proceeds at a higher rate when the SNARE motif is over-expressed. Taken together, this experiment and the inhibition of exocytosis by tomosyn $\Delta \mathrm{CT}$ suggest that the SNARE motif by itself is neither required nor sufficient to inhibit exocytosis in vivo.

\section{The N-terminal WD40-repeat domain of tomosyn is required, but not sufficient for inhibition of exocytosis} We next examined the contribution of the WD40-repeat domain and the hypervariable linker domain to the inhibitory action of tomosyn. In a previous study, the WD40-repeat domain of tomosyn was shown to contain nine wellconserved WD40-repeats, with the last predicted repeat ending at Asp657. Two more repeats were suggested to exist with a smaller degree of homology (Pobbati et al. 2004). To address the importance of the WD40-repeat domain, we constructed a deletion mutant of tomosyn in which the 270 $\mathrm{N}$-terminal amino acids were deleted (tomosyn $\Delta \mathrm{NT}$, Fig. 1a). According to alignment with several WD40-repeat proteins, this deletion encompasses the first 5 of the 9 identified WD40-repeats. We over-expressed this mutated protein in chromaffin cells and examined the responses of overexpressing cells to flash photolysis of caged calcium. The size of the exocytotic burst in cells expressing tomosyn $\Delta \mathrm{NT}$ was indistinguishable from that of control cells (Fig. 4c). However, the sustained component was larger in these cells than that of control cells, indicating an elevated rate of 
(a)

Tomosyn
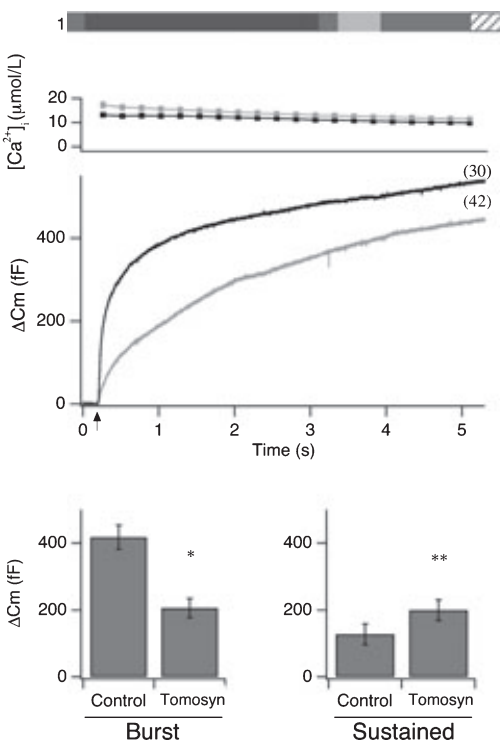

(d)
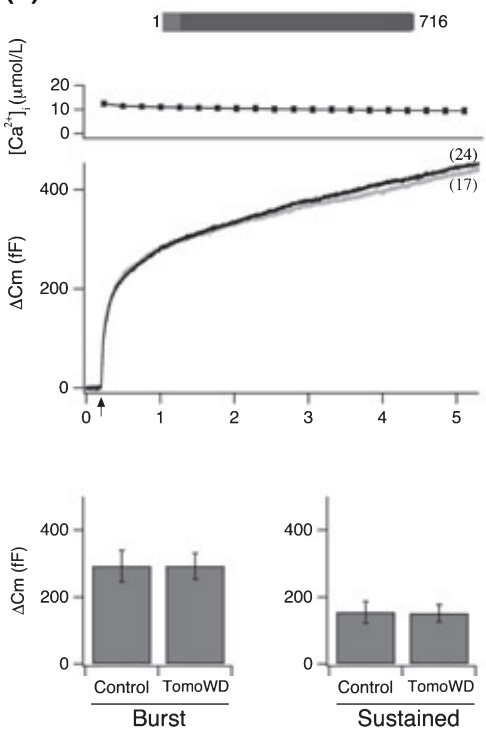

(b)
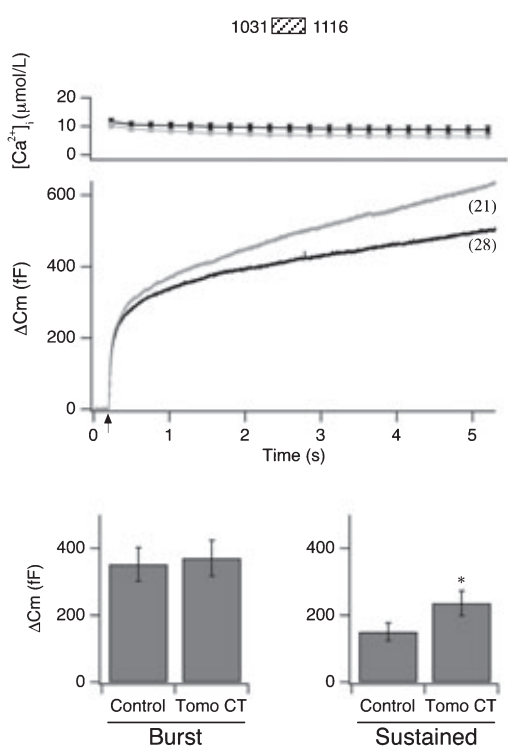

(e)
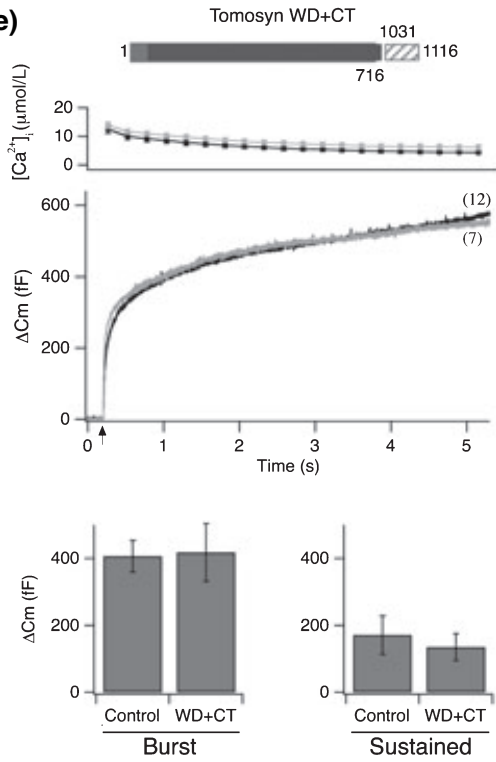

(c)
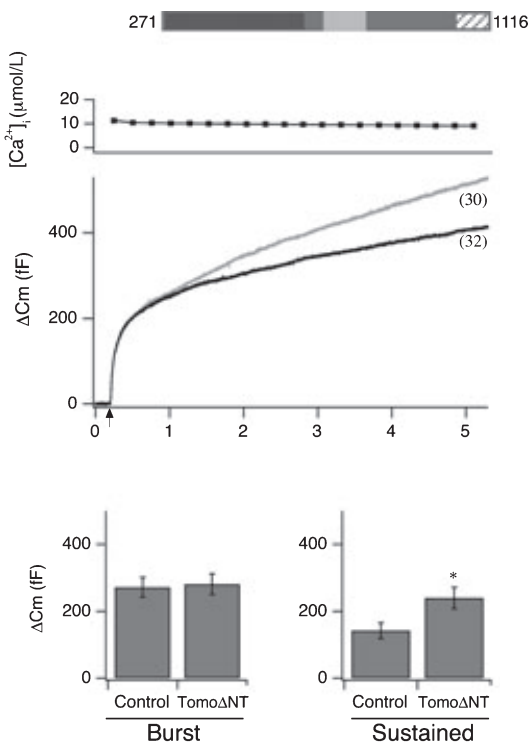

(f)
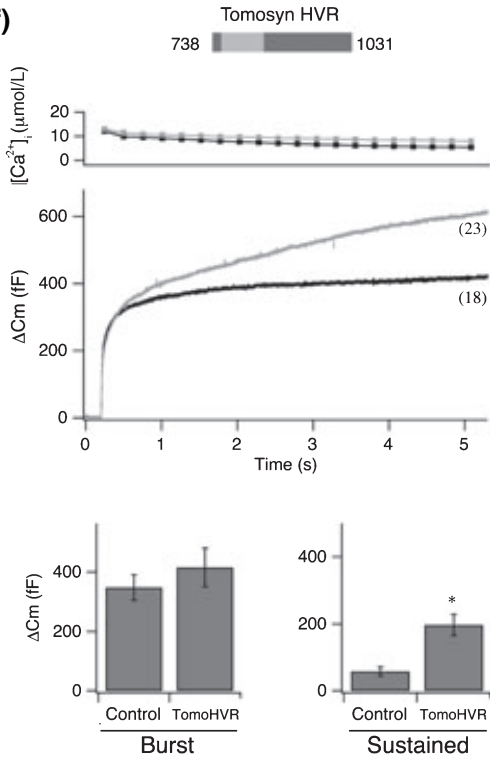

Fig. 4 The tomosyn SNARE motif is dispensable, but the WD-domain is required for inhibition of exocytosis. Each panel shows a diagram of the indicated tomosyn mutant and the result of a flash stimulation in cells over-expressing the full-length or the various tomosyn mutants vs. control cells from the same batch. Averaged calcium $\left(\left[\mathrm{Ca}^{2+}\right]_{1}\right.$, top trace) and capacitance change ( $\mathrm{Cm}$, bottom trace) in control cells (black) and cells over-expressing the indicated tomosyn mutants (gray). Arrows indicate the time of flash stimulation. Bar graphs depict the mean sizes \pm SEM of the exocytotic burst and sustained component in the relevant experiment. (a) Full-length tomosyn causes a significant reduction in the size of the exocytotic burst similar to tomosyn $\Delta C T$ (see Fig. 3a). (b) In cells over-expressing tomosyn $\Delta N T$ the exocytotic burst was similar to control $(280 \pm 30 \mathrm{fF}$ vs.
$280 \pm 32 \mathrm{fF}$, respectively) and the sustained component was slightly enhanced ( $239 \pm 31 \mathrm{fF}$ tomosyn $\Delta \mathrm{NT}$ vs. $147 \pm 24 \mathrm{fF}$ control). (c) In cells over-expressing tomosynCT the exocytotic burst was similar to control ( $388 \pm 51 \mathrm{fF}$ tomosynCT vs. $352 \pm 50 \mathrm{fF}$ control) and the sustained component was slightly enhanced ( $247 \pm 37 \mathrm{fF}$ tomosynCT vs. $150 \pm 27 \mathrm{fF}$ control). The responses of cells expressing tomosynWD (d) and tomosynWD+CC (e) to flash stimulation were identical to the response of control cells. (f) In cells over-expressing the hypervariable linker, the exocytotic burst was similar to control ( $415 \pm 64 \mathrm{fF}$ linker vs. $348 \pm 43 \mathrm{fF}$ control) but the sustained component was significatly enhanced $(196 \pm 32 \mathrm{fF}$ linker vs. $57 \pm 13$ control). ${ }^{*} p<0.05$ (two-tailed student's $t$-test). ${ }^{* *} p<0.005$ (MannWhitney rank-sum test). 
priming that occurs under high $\left[\mathrm{Ca}^{2+}\right]_{\mathrm{i}}$. Since this mutant still binds Syntaxin (Fig. 2a,f), we hypothesized that the WD40repeat region is required for the inhibitory effect of tomosyn.

We thus thought to examine the contribution of the WDdomain itself to the inhibitory effect of tomosyn. We constructed two mutants, one containing amino acids 1-478 of tomosyn (not shown) and another that encompasses amino acids 1-716 (Fig. 1a). The first mutant contains five putative WD40-repeats and the second contains all 9 putative WD40-repeats. None of these mutant proteins inhibited exocytosis when over-expressed in chromaffin cells (Fig. 4d). This suggests that either the WD-domain is not sufficient to inhibit exocytosis or that, by itself, the WDdomain is not correctly folded or targeted to its putative site of action, i.e., membrane microdomains, where exocytosis takes place. This led us to construct a third mutant that contains the WD-domain bound to the SNARE motif at its C-terminal end (Fig. 1a). We reasoned that this mutant will be correctly recruited to the PM via its interaction with Syntaxin and, if the WD-domain is required for the inhibition, it would inhibit exocytosis.

We examined whether the WD+CC mutant binds Syntaxin by GST pull down (Fig. 2a) and using a laser induced photobleach assay (Fig. 2f,h). Both assays showed that this mutant binds Syntaxin at a level comparable to the fulllength protein. We then proceeded to measure the effect of this mutant on exocytosis and found that although this protein binds to Syntaxin both in vitro and in vivo, it did not inhibit exocytosis (Fig. 4e). Thus, we suggest that the WDdomain by itself does not inhibit exocytosis and the combination of the WD and the linker (as in the tomo$\operatorname{syn} \Delta \mathrm{CT}$ mutant) is the minimal region of tomosyn that can modulate exocytosis. Over-expression of the linker region alone did not cause inhibition of the exocytotic burst (Fig 4f). However, cells over-expressing the linker fragment of tomosyn showed an enhanced sustained component (Fig. 4f) as seen in full-length tomosyn and in tomosyn $\Delta \mathrm{CT}$. These data suggest that the N-terminus (combination of WD + linker) constitutes the inhibitory domain of tomosyn while the C-terminal part of tomosyn reflects the permissive parts of the protein.

\section{Discussion}

Previous studies have focused mainly on possible contribution of the coiled-coil domain for tomosyn inhibitory activity. However, the contributions of other domains of tomosyn, which constitute $90 \%$ of the protein, are not known. In the present study, we systematically examined the contribution of the various domains of tomosyn to its activity. Our results indicate that while the interaction with Syntaxin through tomosyn's SNARE-homology domain is not sufficient for inhibition, the integrity of the WD-domain is essential for this effect. In our experiments, all of the tomosyn mutants that contained the SNARE motif (tomosyn $\triangle \mathrm{NT}$, tomosynWD+CT and tomosynCT) bound to Syntaxin in vitro. However, none of these mutants caused any inhibition in exocytosis. Thus, it is clear that a simple model, by which tomosyn titrates Syntaxin through its SNARE-homology domain and thus prevents the formation of SNARE complexes, cannot explain these data. Our findings regarding tomosynCT are in apparent contrast with findings from previous studies that concluded that the SNARE motif of tomosyn is responsible for its inhibitory activity. However, the experiments that led to these conclusions were generally based on an in vitro approach, using recombinant SNARE motif and either membrane sheets from sonicated PC-12 cells or synthetic liposomes (Hatsuzawa et al. 2003; Schuette et al. 2004). The results that we present here indicate that the situation in a living cell might preclude the association of freely diffusing SNARE motifs with Syntaxin. As tomosynWD + CT mutant binds Syntaxin at the PM and tomosynCT does not, it is possible that in vivo, the WD-domain modulates the interaction of the tomosyn SNARE motif with Syntaxin or that this interaction is regulated by other Syntaxin-binding proteins, such as Munc13 and Munc18.

A Syntaxin-independent role for tomosyn and its homolog Amisyn has recently been suggested (Constable et al. 2005) based on mutations in the zero-layers of the SNARE motifs of both proteins. In amysin, this mutation abolished the interaction with Syntaxin in vitro, but did not prevent the inhibitory effect of amysin on exocytosis. In contrast, the mutation in tomosyn only reduced the binding to Syntaxin and did not abolish it. This mutant still inhibited exocytosis. Our results support these findings and further suggest that in the complete absence of the SNARE motif, tomosyn retains most of its inhibitory function. One could suggest that the SNARE motif merely serves to localize tomosyn to its sites of action while the WD/linker domain forms additional protein interactions that are required for inhibition. Nevertheless, as the inhibition imposed by tomosyn $\Delta \mathrm{CT}$ is smaller than the inhibition caused by full-length tomosyn, it is possible that the interaction with Syntaxin is indispensable for the complete inhibitory function of tomosyn in exocytosis. For example, activation of the Rho pathway, e.g., during periods of intense activity, can enhance the binding of Syntaxin to tomosyn via the SNARE motif (Sakisaka et al. 2004). Under these conditions, the tomosyn SNARE motif may be required for activity-dependent modulation of the exocytotic response. However, further work is needed to evaluate this possibility.

These findings led us to hypothesize that the N-terminal region of tomosyn, which contains the WD-domain, plays an important role in the inhibition observed with the tomosyn $\Delta C T$ mutant. Indeed, a partial deletion in the WD-domain completely relieved the inhibitory effect on exocytosis while leaving the Syntaxin interaction intact. This result indicated that the WD-domain is required for tomosyn's function. 
However, further experiments in which the WD-domain was expressed by itself showed that this domain is not sufficient to induce inhibition of vesicle release. We conclude from these findings that protein domains of tomosyn located C-terminally to the WD-domain also are required for its function. Since the linker domain, located C-terminally to the WD-repeat region, did not itself possess any inhibitory effect on exocytosis, it therefore appears that the entire N-terminal region of tomosyn, the WD40-repeats and the linker, is required for this function. This is somewhat surprising, since the linker domain is predicted to be largely unstructured and varies in length between the different tomosyn isoforms (Groffen et al. 2005). However, it is still possible that this domain, with the protein kinase A-phosphorylation site at Ser724 (Baba et al. 2005), might possess an accessory role in the proper function of the putative beta-propeller structure. The notion that the WD and the linker domains are important for proper function of tomosyn is also supported by the findings that a deletion in the $C$. elegans tomosyn homolog (tom1) that encompasses 202 residues located at the $\mathrm{C}$ terminal part of the WD domain created a phenotype similar to that of the tom 1 null mutant and caused enhanced neurotransmitter release (Dybbs et al. 2005; Gracheva et al. 2006; McEwen et al. 2006; Zhang et al. 2006). This conclusion is also supported by the recent publication of the structure of the tomosyn yeast homolog, Sro7 (Hattendorf et al. 2007). Sro 7 contains 14 WD40 repeats that form a twobeta propeller structure, an N-terminal beta propeller and a C-terminal beta propeller that stretches almost to the $\mathrm{C}$ terminus of the protein. According to the structure-based alignment performed in this study, there is a high degree of homology between Sro7 and tomosyn (Hattendorf et al. 2007). Thus, assuming that tomosyn is also folded into a two-beta propeller structure, our results suggest that the integrity of the two propellers is required for tomosyn inhibitory activity as disrupting each of the propellers (The $\mathrm{N}$-terminal one by tomosyn $\Delta \mathrm{NT}$ and the $\mathrm{C}$-terminal one by TomosynWD and TomosynWD+CT), abolished its inhibitory effects. Thus, both propellers are needed to create a functional inhibitory domain and indeed only tomosyn $\Delta \mathrm{CT}$, that contains the N-terminal WD40-domain and the linker (which one can now predict will form the C-terminal beta propeller) inhibits secretion.

From the accumulating evidence regarding tomosyn in recent years, it seems that the effect of tomosyn is not simply to inhibit exocytosis. One would infer that if over-expression of tomosyn causes inhibition, deletion of tomosyn should cause the opposite effect. However, knock-down of tomosyn in neurons and pancreatic beta cells reduced synaptic transmission and insulin secretion, respectively (Baba et al. 2005; Cheviet et al. 2006) but see also Dybbs et al. (2005); Gracheva et al. (2006); McEwen et al. (2006); Zhang et al. (2006) for opposite effects. Thus, it could be suggested that tomosyn possesses an additional, permissive role that is eliminated when tomosyn is knocked down. The enhanced sustained component seen in several tomosyn mutants indicate that domains located C-terminally to the WD40repeats (linker and the $\mathrm{C}$-Terminal part of the protein) might be involved in such a permissive role and serve to potentiate secretion. Alternatively, it is possible that tomosyn has an optimal concentration range and any shift from this concentration will cause inhibition (Baba et al. 2005).

In summary, our results suggest that tomosyn has multiple functional domains that regulate its activity. Although tomosyn interacts with Syntaxin through its SNARE motif, it inhibits exocytosis independently of the SNARE motif. This interaction may be dynamically regulated by external stimulations and can enhance the inhibitory effect of tomosyn. We further show that the inhibitory function of tomosyn depends on the integrity of the N-terminal WD40domain and that the entire protein domain, $\mathrm{N}$-terminally to the SNARE motif, is required for tomosyn's effect. These data suggest that the WD40-domain and the linker form an integral functional domain (Baba et al. 2005; Betschinger et al. 2005; Hattendorf et al. 2007) that is responsible for tomosyn's inhibitory activity.

\section{Acknowledgements}

We would like to thank Prof. Ilana Lotan for help with plasmids and materials, members of our groups for stimulating discussions and suggestions and Rely Melamed for expert technical assistance. This study was supported by grants from the Adams supercenter for brain studies, the Israel Science Foundation (grant 424/02-16.6), the Minerva Junior Research Group (to UA), the Deutsche Forschungsgemeinschaft (GRK 845 and SFB 530 to JR) and by grants from the National Institutes of Health (NS39914, E.L.S., NIDDK, P60DK20572 and P60DK20572, S.A.E.) and the National Institutes of Health (RO1 NS053978; E.L.S and U.A.).

\section{Supplementary material}

The following supplementary material is available for this article online:

Fig. S1 Expression of tomosyn mutants.

This material is available as part of the online article from http:// www.blackwell-synergy.com

\section{References}

Ashery U., Betz A., Xu T., Brose N. and Rettig J. (1999) An efficient method for infection of adrenal chromaffin cells using the Semliki forest virus gene expression system. Eur. J. Cell Biol. 78, 525-532.

Ashery U., Varoqueaux F., Voets T., Betz A., Thakur P., Koch H., Neher E., Brose N. and Rettig J. (2000) Munc13-1 acts as a priming factor for large dense-core vesicles in bovine chromaffin cells. EMBO J. 19, 3586-3596.

Augustine G. J., Burns M. E., DeBello W. M., Hilfiker S., Morgan J. R., Schweizer F. E., Tokumaru H. and Umayahara K. (1999) Proteins involved in synaptic vesicle trafficking. J. Physiol. 520, 33-41. 
Baba T., Sakisaka T., Mochida S. and Takai Y. (2005) PKA-catalyzed phosphorylation of tomosyn and its implication in $\mathrm{Ca}^{2+}$-dependent exocytosis of neurotransmitter. J. Cell Biol. 170, 11131125

Becherer U. and Rettig J. (2006) Vesicle pools, docking, priming, and release. Cell Tissue Res. 326, 393-407.

Betschinger J., Eisenhaber F. and Knoblich J. A. (2005) Phosphorylation-induced autoinhibition regulates the cytoskeletal protein Lethal (2) giant larvae. Curr. Biol. 15, 276-282.

Calakos N. and Scheller R. H. (1996) Synaptic vesicle biogenesis, docking, and fusion: a molecular description. Physiol. Rev. 76, $1-29$.

Castillo P. E., Schoch S., Schmitz F., Sudhof T. C. and Malenka R. C. (2002) RIMlalpha is required for presynaptic long-term potentiation. Nature 415, 327-330.

Cheviet S., Bezzi P., Ivarsson R., Renstrom E., Viertl D., Kasas S., Catsicas S. and Regazzi R. (2006) Tomosyn-1 is involved in a postdocking event required for pancreatic \{beta\}-cell exocytosis. J. Cell Sci. 119, 2912-2920.

Constable J. R., Graham M. E., Morgan A. and Burgoyne R. D. (2005) Amisyn regulates exocytosis and fusion pore stability by both syntaxin-dependent and syntaxin-independent mechanisms. J. Biol. Chem. 280, 31615-31623.

Dybbs M., Ngai J. and Kaplan J. M. (2005) Using microarrays to facilitate positional cloning: identification of tomosyn as an inhibitor of neurosecretion. J. Physiology 1, 6-16.

Fasshauer D., Eliason W. K., Brunger A. T. and Jahn R. (1998) Identification of a minimal core of the synaptic SNARE complex sufficient for reversible assembly and disassembly. Biochemistry 37, 10354-10362.

Fernandez-Chacon R. and Sudhof T. C. (1999) Genetics of synaptic vesicle function: toward the complete functional anatomy of an organelle. Annu. Rev. Physiol. 61, 753-776.

Fujita Y., Shirataki H., Sakisaka T. et al. (1998) Tomosyn: a syntaxin-1binding protein that forms a novel complex in the neurotransmitter release process. Neuron 20, 905-915.

Gerst J. E. (1999) SNAREs and SNARE regulators in membrane fusion and exocytosis. Cell Mol. Life Sci. 55, 707-734.

Gracheva E. O., Burdina A. O., Holgado A. M., Berthelot-Grosjean M., Ackley B. D., Hadwiger G., Nonet M. L., Weimer R. M. and Richmond J. E. (2006) Tomosyn Inhibits Synaptic Vesicle Priming in Caenorhabditis elegans. PLos Biol. 4, 1426-1437.

Groffen A. J., Jacobsen L., Schut D. and Verhage M. (2005) Two distinct genes drive expression of seven tomosyn isoforms in the mammalian brain, sharing a conserved structure with a unique variable domain. J. Neurochem. 92, 554-568.

Hanson P. I., Roth R., Morisaki H., Jahn R. and Heuser J. E. (1997) Structure and conformational changes in NSF and its membrane receptor complexes visualized by quick-freeze/deep-etch electron microscopy. Cell 90, 523-535.

Hatsuzawa K., Lang T., Fasshauer D., Bruns D. and Jahn R. (2003) The R-SNARE motif of tomosyn forms SNARE core complexes with syntaxin 1 and SNAP-25 and down-regulates exocytosis. J. Biol. Chem. 278, 31159-31166.

Hattendorf D. A., Andreeva A., Gangar A., Brennwald P. J. and Weis W. I. (2007) Structure of the yeast polarity protein Sro7 reveals a SNARE regulatory mechanism. Nature 446, 567-571.

Henkel A. W. and Almers W. (1996) Fast steps in exocytosis and endocytosis studied by capacitance measurements in endocrine cells. Curr. Opin. Neurobiol. 6, 350-357.

Jahn R. and Sudhof T. C. (1999) Membrane fusion and exocytosis. Annu. Rev. Biochem. 68, 863-911.

Lehman K., Rossi G., Adamo J. E. and Brennwald P. (1999) Yeast homologues of tomosyn and lethal giant larvae function in exo- cytosis and are associated with the plasma membrane SNARE, Sec9. J. Cell Biol. 146, 125-140.

Lonart G. (2002) RIM1: an edge for presynaptic plasticity. Trends Neurosci. 25, 329-332.

Lonart G. and Sudhof T. C. (2000) Assembly of snare core complexes occurs prior to neurotransmitter release to set the readily-releasable pool of synaptic vesicles. J. Biol. Chem. 275, 27703-27707.

Masuda E. S., Huang B. C., Fisher J. M., Luo Y. and Scheller R. H. (1998) Tomosyn binds t-SNARE proteins via a VAMP-like coiled coil. Neuron 21, 479-480.

McEwen J. M., Madison J. M., Dybbs M. and Kaplan J. M. (2006) Antagonistic Regulation of Synaptic Vesicle Priming by Tomosyn and UNC-13. Neuron 51, 303-315.

Musch A., Cohen D., Yeaman C., Nelson W. J., Rodriguez-Boulan E. and Brennwald P. J. (2002) Mammalian homolog of Drosophila tumor suppressor lethal (2) giant larvae interacts with basolateral exocytic machinery in Madin-Darby canine kidney cells. Mol. Biol. Cell 13, 158-168.

Neer E. J., Schmidt C. J., Nambudripad R. and Smith T. F. (1994) The ancient regulatory-protein family of WD-repeat proteins. Nature 371, 297-300.

Neher E. (1998) Vesicle pools and Ca2+ microdomains: new tools for understanding their roles in neurotransmitter release. Neuron 20, 389-399.

Nili U., de Wit H., Gulyas-Kovacs A., Toonen R. F., Sorensen J. B., Verhage M. and Ashery U. (2006) Munc18-1 phosphorylation by protein kinase $\mathrm{C}$ potentiates vesicle pool replenishment in bovine chromaffin cells. Neuroscience 143, 487-500.

Plattner H., Artalejo A. R. and Neher E. (1997) Ultrastructural organization of bovine chromaffin cell cortex-analysis by cryofixation and morphometry of aspects pertinent to exocytosis. J. Cell Biol. 139, 1709-1717.

Pobbati A. V., Razeto A., Boddener M., Becker S. and Fasshauer D. (2004) Structural basis for the inhibitory role of tomosyn in exocytosis. J. Biol. Chem. 279, 47192-47200.

Reid C. A., Dixon D. B., Takahashi M., Bliss T. V. and Fine A. (2004) Optical quantal analysis indicates that long-term potentiation at single hippocampal mossy fiber synapses is expressed through increased release probability, recruitment of new release sites, and activation of silent synapses. J. Neurosci. 24, 3618-3626.

Rettig J. and Neher E. (2002) Emerging roles of presynaptic proteins in $\mathrm{Ca}^{++}$-triggered exocytosis. Science 298, 781-785.

Richmond J. and Broadie K. (2002) The synaptic vesicle cycle: exocytosis and endocytosis in Drosophila and C. elegans. Curr. Opin. Neurobiol. 12, 499.

Rosenmund C., Sigler A., Augustin I., Reim K., Brose N. and Rhee J. S. (2002) Differential control of vesicle priming and short-term plasticity by Munc13 isoforms. Neuron 33, 411-424.

Sakisaka T., Baba T., Tanaka S., Izumi G., Yasumi M. and Takai Y. (2004) Regulation of SNAREs by tomosyn and ROCK: implication in extension and retraction of neurites. J. Cell Biol. 166, 1725 .

Scales S. J., Hesser B. A., Masuda E. S. and Scheller R. H. (2002) Amisyn, a novel syntaxin-binding protein that may regulate SNARE complex assembly. J. Biol. Chem. 277, 28271-2829.

Schuette C. G., Hatsuzawa K., Margittai M., Stein A., Riedel D., Kuster P., Konig M., Seidel C. and Jahn R. (2004) Determinants of liposome fusion mediated by synaptic SNARE proteins. Proc. Natl Acad. Sci. USA 101, 2858-2863.

Smith T. F., Gaitatzes C., Saxena K. and Neer E. J. (1999) The WD repeat: a common architecture for diverse functions. Trends Biochem. Sci. 24, 181-185.

Sørensen J. B., Matti U., Wei S. H., Nehring R. B., Voets T., Ashery U., Binz T., Neher E. and Rettig J. (2002) The SNARE protein SNAP-25 
is linked to fast calcium triggering of exocytosis. Proc Natl Acad Sci USA. 99, 1627-132.

Sørensen J. B., Nagy G., Varoqueaux F., Nehring R. B., Brose N., Wilson M. C. and Neher E. (2003) Differential control of the releasable vesicle pools by SNAP-25 splice variants and SNAP-23. Cell 114, 75-86.

Sudhof T. C. (2004) The synaptic vesicle cycle. Annu. Rev. Neurosci. 27, 509-547.

Sutton R. B., Fasshauer D., Jahn R. and Brunger A. T. (1998) Crystal structure of a SNARE complex involved in synaptic exocytosis at 2.4 A resolution. Nature 395, 347-353.

Voets T., Neher E. and Moser T. (1999) Mechanisms underlying phasic and sustained secretion in chromaffin cells from mouse adrenal slices. Neuron 23, 607-615.

Weber T., Zemelman B. V., McNew J. A., Westermann B., Gmachl M., Parlati F., Sollner T. H. and Rothman J. E. (1998) SNAREpins: minimal machinery for membrane fusion. Cell 92, 759-772.

Weis W. I. and Scheller R. H. (1998) Membrane fusion. SNARE the rod, coil the complex. Nature 395, 328-329.

Widberg C. H., Bryant N. J., Girotti M., Rea S. and James D. E. (2003) Tomosyn interacts with the t-SNAREs syntaxin4 and SNAP23 and plays a role in insulin-stimulated GLUT4 translocation. J. Biol. Chem. 278, 35093-35101.
Xu T. and Bajjalieh S. M. (2001) SV2 modulates the size of the readily releasable pool of secretory vesicles. Nat. Cell Biol. 3, 691-68.

Xu T., Binz T., Niemann H. and Neher E. (1998) Multiple kinetic components of exocytosis distinguished by neurotoxin sensitivity. Nat. Neurosci. 1, 192-200.

Xu T., Rammner B., Margittai M., Artalejo A. R., Neher E. and Jahn R. (1999) Inhibition of SNARE complex assembly differentially affects kinetic components of exocytosis. Cell 99, 713-722.

Yizhar O., Matti U., Melamed R., Hagalili Y., Bruns D., Rettig J. and Ashery U. (2004) Tomosyn inhibits priming of large dense-core vesicles in a calcium-dependent manner. Proc. Natl Acad. Sci. USA 101, 2578-2583.

Yokoyama S., Shirataki H., Sakisaka T. and Takai Y. (1999) Three splicing variants of tomosyn and identification of their syntaxin- binding region. Biochem. Biophys. Res. Commun. 256, $218-222$.

Zhang W., Lilja L., Mandic S. A., Gromada J., Smidt K., Janson J., Takai Y., Bark C., Berggren P. O. and Meister B. (2006) Tomosyn is expressed in beta-cells and negatively regulates insulin exocytosis. Diabetes 55, 574-581.

Zucker R. S. and Regehr W. G. (2002) Short-term synaptic plasticity. Annu. Rev. Physiol. 64, 355-405. 